\title{
Desenvolvimento e avaliação de sistema multimídia para ensino e aprendizado de irrigação
}

\author{
Rubens A. Oliveira ${ }^{1}$, Renata da S. Mota ${ }^{2}$, Carlos V. Farias ${ }^{3}$, Leacir N. Bastos ${ }^{3}$ \& Márcio M. Ramos \\ 'DEA/UFV, Viçosa, MG. Fone: (31) 3899-1909, Fax: (31) 3899-2735. E-mail: ralves@ufv.br (Foto) \\ 2 DEA/UFV. E-mail: renapeter@yahoo.com \\ 3 DEA/UFV. E-mail: cvfarias@ufv.br, Inb@dpi.ufv.bre mmramos@ufv.br
}

Protocolo $19-22 / 2 / 2002$

\begin{abstract}
Resumo: Este trabalho possibilitou desenvolver-se e avaliar um software educacional utilizando recursos hipermídia, voltado para o ensino e aprendizado de irrigação, denominado "Curso Básico de Irrigação: Sistemas e Manejo", que consta de um CD-Rom dividido em 7 capítulos, acompanhado de manual. Para elaboração do software foi constituída uma equipe multidisciplinar com profissionais das áreas de Irrigação, Educação e Ciência da Computação. O pressuposto teórico para desenvolvimento do curso foi o "behaviorismo". Na avaliação do software foram distribuídas cópias do CD-Rom a produtores rurais em Janaúba, MG, e Sousa, PB, e a estudantes de cursos de nível médio e de graduação ligados à área agrícola, nas cidades de Rio Pomba, Viçosa, e Montes Claros, MG, e em Sousa, PB. Solicitou-se que cada participante da pesquisa avaliasse o CD-Rom como um todo, sob o aspecto didático e, em seguida, focasse a atenção em apenas um capítulo do software, distribuído por sorteio, para que pudesse responder a ficha de avaliação. Os resultados obtidos foram separados por grupo avaliado: Grupo A (Produtor rural); Grupo B (Estudantes de nível médio) e Grupo C (Estudantes de nível superior) e os dados agrupados por categoria avaliada: interface, conteúdo e interatividade. A avaliação conduzida com o público ao qual foi destinado o software, indicou média de 6,87 , valor próximo ao considerado "muito" na escala de Likert, indicando que o sistema multimídia desenvolvido pode ser utilizado como recurso didático no ensino e aprendizado de irrigação.
\end{abstract}

Palavras-chave: irrigação, software educacional, multimídia

\section{Development and evaluation of teaching-learning multimedia system for irrigation}

\begin{abstract}
This work was carried out to develop and evaluate an educational software for irrigation by using hypermedia resources, for teaching and learning of "Irrigation Basic Course: Systems and Management". It was organized in a CD-Rom divided in 7 chapters and provided with a manual. For elaborating the software, a multidisciplinary team of professionals in the areas of Irrigation, Education and Computer Science was constituted. The theoretical assumption for course development was "behavioristic". Copies of CD-Rom were distributed to farmers in Janaúba, MG, and Sousa, PB, and among High School and College level students related to the agricultural area in the cities of Rio Pomba, Viçosa and Montes Claros, MG, and Sousa, PB. Each participant was requested to evaluate the CD-Rom as a whole, considering the didactic aspect, and after that to concentrate on just one chapter of the software, so that he/she could answer a questionnaire. The results were separated by appraised groups: Group A (farmers); Group B (High School students) and Group C (College students), and the data contained were appraised by category: interface, content and interactivity category. The evaluation indicated a mean value of 6.87 considered to be 'a lot' in the Likert scale, indicating that the software can be used as a didactic resource for the teaching and learning of irrigation.
\end{abstract}

Key words: irrigation, educational software, multimedia

\section{INTRODUÇÃO}

A irrigação compreende um conjunto de técnicas que visam satisfazer principalmente as necessidades hídricas das culturas.
A decisão de irrigar e a quantificação das necessidades de água dependem de vários fatores, como o tipo de solo, o clima, as fontes de abastecimento d'água disponíveis, o estudo mercadológico, a viabilidade econômica do processo produtivo, 
as características ambientais locais, a disponibilidade de equipamentos e insumos, além de todos os processos sociais envolvidos. Dentro deste conjunto, pode-se dizer que a irrigação se constitui numa atividade imprescindível no contexto de uma agricultura rentável, em quase todas as regiões e climas do nosso planeta (Gomes, 1994).

Uma das maneiras de se difundir a tecnologia de irrigação, é por meio dos diversos recursos da informática. O surgimento das mídias eletrônicas, que divulgam o conhecimento produzido e o acesso à informação que, por sua vez, se constituem pilares da educação ocidental moderna, acontecem de forma cada vez mais ágil e, com isto, os critérios de perenidade e permanência dos conhecimentos acumulados se somam ao critério de atualidade (Carvalho \& Botelho, 2001).

De acordo com Moreira (1986) o processo de informatização da educação deve ser considerado como meio de ampliação das funções do professor, favorecendo mudanças nas condições e no processo ensino-aprendizagem. A modernização das técnicas de ensino, no entanto, só logrará êxito se usada de forma crítica pelos usuários, de modo geral, visto que deverá estar associada a cada realidade educativa e fundamentada em princípios psicopedagógicos que explicitem certa concepção de ensino e aprendizagem. Em termos pedagógicos, pode-se afirmar que a didática de mídia ainda segue muitos conceitos da tecnologia instrucional tradicional, visto se basear em psicologia comportamentalista (behaviorista) cujos passos básicos são: a análise da tarefa; o avanço em pequenos e progressivos passos de aprendizagem; a participação ativa do estudante; a velocidade de aprendizagem individual e a realimentação imediata do esforço.

O software educacional pode ser visto tanto como uma construção técnica como recurso pedagógico. Do ponto de vista técnico, compreende a parte computacional e é avaliado em termos de sua organização lógica e desempenho. Quanto ao fato de ser um recurso pedagógico, a principal questão corresponde à contribuição do software para o ensino e aprendizagem do seu público alvo (Focking, 2001).

Segundo Brandão (2001) o conhecimento das características que tornam o software adequado ou não ao processo ensinoaprendizagem, das modalidades de interação que estabelece com o usuário e de sua inter-relação com os objetivos educacionais em específicas situações de ensino, é de fundamental importância para o êxito da relação entre informática e educação.

Para Oliveira (1998) citado por Focking (2001), o software educacional é um programa de computador que possui uma proposta de ensino, com um objetivo educacional predefinido, que se propõe a auxiliar na aprendizagem de conteúdos e habilidades, mediante a utilização de uma interface computadorizada. O software deve possuir recursos que auxiliem no processo de aquisição de determinado conhecimento, promovendo situações estimulantes para o aluno, não apenas despertando a sua atenção, mas mantendo-a ao longo de sua interação. Para que este propósito seja atingido, os conteúdos pedagógicos apresentados no software educacional devem ser claros, consistentes, compreensíveis. Recursos multimídia e recursos motivacionais devem provocar o interesse pelo assunto ao mesmo tempo em que facilitam a relação ensino/ aprendizagem.
Há, portanto, o consenso de que o software educacional deve atender aos objetivos específicos e fazer uso de recursos que potencializem o processo não só de aquisição, mas também, de reforço de determinados conhecimentos e habilidades, estimulando o desenvolvimento cognitivo do usuário, permitindo um aprendizado expressivo.

Nesse contexto, este trabalho teve como objetivo desenvolver e avaliar um software educacional sobre irrigação com recursos hipermídia, tendo como suporte pedagógico a teoria comportamentalista (behaviorista) e destinado ao meio rural e acadêmico ligado às ciências agrárias.

\section{MATERIAL E MÉTODOS}

O presente trabalho foi fruto de parceria entre o Departamento de Engenharia Agrícola da Universidade Federal de Viçosa e o Centro de Produções Técnicas (CPT) sediado em Viçosa, Minas Gerais. Sua realização contou com uma equipe multidisciplinar, constituída por profissionais das áreas de engenharia de irrigação, ciência da computação, educação, projeto de software, produção e edição de vídeos e animações gráficas. A estrutura do curso básico de irrigação foi programada de tal maneira que o usuário pudesse acessar livremente as diversas unidades do CD-Rom, usando a estrutura hipermídia, de forma seqüenciada ou não. O desenvolvimento do software foi constituído das etapas descritas a seguir:

Projeto: Etapa em que o diretor e o coordenador definiram e organizaram as entidades (tópicos ou capítulos) e blocos de informações (sub-tópicos) que deveriam constar no curso.

Interação: Etapa em que o diretor apresentou e discutiu com os programadores visual (designer) e de software (autoria) a estrutura do CD-Rom, em termos de conteúdo e de distribuição das entidades e dos blocos de informações. A função do programador visual nesta etapa foi buscar informações que o auxiliassem na elaboração da interface, baseado em conceitos de semiótica da interface e da necessidade de conhecimento do assunto e do público alvo. Ao programador de software coube, nesta etapa, conhecer o projeto e discutir com o diretor as configurações mínimas e máximas a serem utilizadas no CD-Rom.

Instanciação: A instanciação corresponde à parte operacional do software e os conceitos de hipermídia são importantes nesta fase, quando são criados os mapas de informação para apresentação do conteúdo, tornando-se imprescindível a participação do pedagogo que irá direcionar o uso das mídias, de acordo com as necessidades que julga importantes para determinada exposição. O contato com o aprendiz é a mensagem principal que o mesmo considera para delinear o uso das mídias. Esta etapa foi usada para se definir as navegações e estruturas de acesso nas entidades e blocos de informações.

Story Board e Script Book: A confecção dos Story Boards e dos Script Books consistiu na elaboração das informações visuais e dos comandos mostrados em cada tela, envolvendo a participação do diretor e dos programadores visual e de autoria. O uso de mídias nesta etapa foi discutido exaustivamente, para que o diretor pudesse criar com liberdade, sem comprometer a qualidade técnica do projeto. 
Interface: A etapa denominada interface foi de responsabilidade do programador visual que, de posse das informações coletadas na fase de interação e com os Story Boards e Scripts Books em mãos, passou a dar forma a cada tela do CD-Rom. Segundo Souza (1993) a interface é composta de mensagens enviadas do programador visual para o usuário, de tal modo que cada usuário, por sua vez, pode enviar e receber mensagens. Assim, uma interface requer, do programador visual, um processo de produção de mensagens e, dos usuários, a interpretação dessas mensagens. A linguagem simbólica adotada pelo programador visual deve contemplar a percepção cognitiva do usuário para que a navegação possa fluir de maneira agradável, possibilitando a ampliação da capacidade de entendimento, memorização e tomada de decisão por parte do usuário.

Mídias: As mídias podem ser dinâmicas, como vídeos, sons e animações gráficas, ou estáticas, tais como textos e imagens digitalizadas. $\mathrm{O}$ termo multimídia se refere à apresentação e recuperação de informações, que se faz com o auxílio do computador, de maneira multissensorial e interativa. Esta etapa foi desenvolvida logo após a elaboração dos Story Boards e Script Books, paralelamente à etapa de interface.

Autoria: A fase de autoria, também denominada implementação, consistiu em implementar o projeto numa linguagem computacional com recursos hipermídia.

Validação: Após a implementação pela autoria, foi passado ao diretor e ao coordenador do projeto, um protótipo do CD-Rom para que os mesmos pudessem fazer uma avaliação técnica. A etapa de validação do CD-Rom é a última fase em que são permitidas alterações de conteúdo, podendo acarretar mudanças nas fases anteriores.

Teste: Após terminada a aplicação, foram feitos os testes " $\alpha$ " e " $\beta$ " necessários para validação do produto e que correspondem, respectivamente, às primeira e segunda etapas de testes e correções. Após os testes, o software ficou pronto para reprodução e comercialização.

Na avaliação do software foram distribuídas cópias do CDRom a produtores rurais em Janaúba, MG, e Sousa, PB, e a estudantes de cursos de nível médio e de graduação ligados à área agrícola, nas cidades de Rio Pomba, Viçosa e Montes Claros, MG, e em Sousa, PB. Solicitou-se que cada participante da pesquisa, 56 pessoas envolvidas, avaliasse o CD-Rom como um todo sob o aspecto didático e, em seguida, focasse a atenção em apenas um capítulo do software (distribuído por sorteio) para que pudesse responder a uma ficha de avaliação, a qual consistiu de um questionário aplicado com a finalidade de avaliar a função educacional do software, contemplando: 1) a facilidade de acesso às telas; 2) a seqüência das unidades do CD-Rom; 3) a quantidade de informações no CD-Rom; 4) a qualidade dos vídeos; 5) a qualidade dos áudios; 6) a qualidade das fotos digitais; 7) a qualidade das animações gráficas; 8) a qualidade das informações escritas; 9) se os exemplos, exercícios e resumos apresentados foram importantes para o aprendizado do conteúdo; 10) se o CD-Rom atendeu às expectativas do usuário, em termos teóricos; e 11) se o CDRom atendeu às expectativas do usuário, em termos práticos.

Os avaliadores foram identificados por uma letra, referente ao grupo a que pertenciam (A, B, C) e um número (1, 2, 3 etc.) representando a ordem de entrega da ficha de avaliação. Os resultados obtidos foram separados por grupo avaliado: Grupo A (Produtor rural); Grupo B (Estudantes de nível médio) e Grupo C (Estudantes de nível superior) e os dados agrupados por categoria avaliada: interface, conteúdo e interatividade. Do modelo de ficha de avaliação adotado na pesquisa, foi aplicada a escala de Likert, a qual é representada da seguinte maneira: 1 a 3: pouco; 4 a 6: mais ou menos e 7 a 9: muito.

\section{RESULTADOS E DISCUSSÃO}

O software elaborado foi denominado "Curso Básico de Irrigação: Sistemas e Manejo", sendo auto-executável e desenvolvido em ambiente Windows. O curso consta de sete capítulos, os quais são apresentados na tela do menu principal, conforme ilustra a Figura 1.

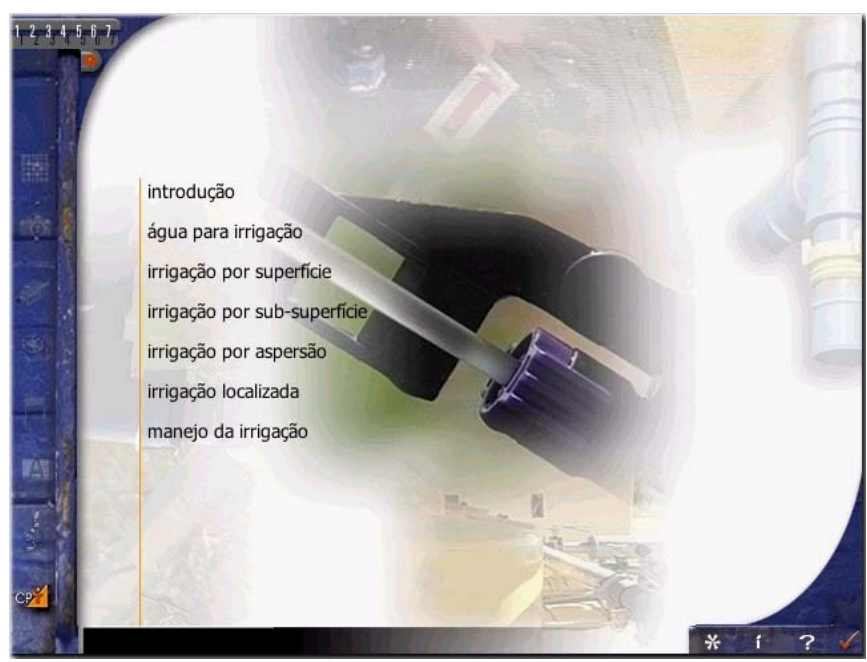

Figura 1. Tela do menu principal com os sete capítulos e ícones de navegação

O conteúdo de cada capítulo está apresentado em itens e subitens, com exercícios resolvidos e propostos, e resumo final para fixação dos assuntos abordados. Os ícones de navegação estão descritos no manual que acompanha o CD-Rom.

O Capítulo 1 aborda aspectos relacionados à irrigação no Brasil e no mundo, além de conceitos básicos sobre irrigação, tais como capacidade de campo, ponto de murcha permanente, densidade do solo e evapotranspiração, dentre outros.

O Capítulo 2 ressalta aspectos relacionados à água, como a qualidade, quantidade e outorga.

O Capítulo 3 apresenta o método de irrigação por superfície, com os diversos sistemas e suas principais características, enquanto o 4 mostra as características de sistemas de irrigação por sub-superfície por meio de estabelecimento de lençol freático constante e variável e, no Capítulo 5 , é apresentado o método de irrigação por aspersão, abrangendo os diversos sistemas: aspersão convencional, autopropelido, pivô central, pivô móvel, barra irrigadora e LEPA, dentre outros.

O Capítulo 6 mostra o método de irrigação localizada, caracterizando os sistemas de gotejamento e microaspersão, e o Capítulo 7 apresenta métodos aplicados no manejo da irrigação. 
Todos os capítulos foram escritos com linguagem acessível a um público diversificado, constituído por produtores rurais, estudantes de nível médio e estudantes de graduação.

As mídias dinâmicas utilizadas no software, como animações e vídeos, foram de particular importância na percepção de conceitos difíceis de ser compreendidos apenas com textos, como é o caso de capacidade de campo, ponto de murcha permanente e evapotranspiração. Nesses casos, as animações foram de fundamental significação para contextualização do assunto.

A Tabela 1 apresenta os valores médios relativos à avaliação da interface do software, de acordo com a escala de Likert, para os três grupos avaliadores, para as questões $1,4,5,6$ e 7 da ficha de avaliação proposta.

Tabela 1. Valores médios relativos à avaliação da interface, de acordo com a escala de Likert

\begin{tabular}{cccccc}
\hline \multirow{2}{*}{ Avaliador } & \multicolumn{5}{c}{ Questão } \\
\cline { 2 - 6 } & 1 & 4 & 5 & 6 & 7 \\
\hline Grupo A & 4,3 & 8,0 & 6,5 & 8,0 & 6,8 \\
Grupo B & 6,5 & 7,2 & 7,6 & 7,2 & 6,5 \\
Grupo C & 6,7 & 6,9 & 7,9 & 7,5 & 6,9 \\
\hline
\end{tabular}

Os valores da escala de Likert para a interface avaliada pelos usuários indicam que, para os três grupos, houve uma boa relação homem-máquina. O valor médio para os três grupos, nesta escala, foi de 6,97. Para os três grupos observou-se, também, que os menores valores foram para a questão " 1 ": "Facilidade de acesso às telas". Os menores valores atribuídos ocorreram no grupo " $\mathrm{A}$ ", em que dois produtores rurais responderam, no questionário, que nunca usaram a Internet e, também, que jamais fizeram uso de outros softwares educacionais, o que certamente resulta em dificuldade de acesso às telas.

A Tabela 2 apresenta os valores médios relativos à avaliação do conteúdo, de acordo com a escala de Likert, para os três grupos avaliadores, para as questões 2,3 e 8 da ficha de avaliação proposta.

Tabela 2. Valores médios relativos à avaliação do conteúdo, de acordo com a escala de Likert

\begin{tabular}{cccc}
\hline \multirow{2}{*}{ Avaliador } & \multicolumn{3}{c}{ Questão } \\
\cline { 2 - 4 } & 2 & 3 & 8 \\
\hline Grupo A & 6,2 & 7,5 & 7,8 \\
Grupo B & 7,1 & 6,4 & 6,2 \\
Grupo C & 7,3 & 6,5 & 7,4 \\
\hline
\end{tabular}

O conteúdo avaliado pelos três grupos aponta um valor médio de 6,9 pontos na escala de Likert, indicando que o conteúdo proposto atendeu às expectativas dos usuários, embora possuam diferentes níveis de informação sobre irrigação. Os grupos "A" (Produtor rural) e " $C$ " (Estudantes de nível superior) obtiveram as maiores médias, o primeiro, possivelmente, pela carência de informações no meio rural, e o segundo por conseguir entender que se trata de um curso básico e, ainda, por avaliar o "software" como um recurso adicional em sala de aula.
Por fim, a Tabela 3 apresenta os valores médios relativos à avaliação da interatividade, de acordo com a escala de Likert, para os três grupos avaliadores, para as questões 9, 10 e 11 da ficha de avaliação proposta.

Tabela 3. Valores médios relativos à avaliação da interatividade, de acordo com a escala tipo Likert

\begin{tabular}{cccc}
\hline \multirow{2}{*}{ Avaliador } & \multicolumn{3}{c}{ Questão } \\
\cline { 2 - 4 } & 9 & 10 & 11 \\
\hline Grupo A & 6,2 & 7,5 & 7,8 \\
Grupo B & 6,4 & 6,2 & 4,8 \\
Grupo C & 6,7 & 7,1 & 7,1 \\
\hline
\end{tabular}

A interatividade avaliada pelos grupos apontou uma média geral de 6,6 pontos na escala de Likert, indicando que o software atendeu às expectativas dos usuários, como recurso de autoaprendizagem. O grupo "B" obteve a menor média $(4,8)$ e foi o grupo que considerou os textos (parte teórica) uma das mídias mais importantes. As perguntas 9, “Os exemplos, exercícios e resumos apresentados foram importantes para o fechamento do conteúdo?", e 10, "Em termos teóricos, o CD-Rom atendeu às suas expectativas?" referiam-se à interatividade sob o aspecto teórico, o que, possivelmente, explica os baixos valores obtidos para este grupo. A média geral, considerando-se as três categorias avaliadas (interface, conteúdo e interatividade) foi 6,87 , valor próximo à classificação "muito" na escala de Likert.

Os interessados em obter o CD-Rom e o manual, ao preço de custo, devem contactar o primeiro autor.

\section{CONCLUSÃO}

$\mathrm{Na}$ avaliação conduzida com o público ao qual foi destinado o software, obteve-se média igual a 6,87 , valor próximo ao considerado "muito" na escala de Likert, indicando que o sistema multimídia desenvolvido pode ser utilizado como recurso didático no ensino e aprendizado de irrigação atingindo, de maneira satisfatória, estudantes e produtores rurais, os quais se mostraram receptivos a esta nova tecnologia.

\section{LITERATURA CITADA}

Brandão, E.J.R. Repensando modelos de avaliação do software educacional. http://www.minerva.uevora.pt/simposio/ comunicacoes/artigo.html (18 jan 2001).

Carvalho, G.M.G.; Botelho, F.V.U. Educação à Distância: um estudo sobre expectativas dos alunos em relação ao uso do meio impresso ou eletrônico. http://www.intelecto.net/ ead_textos/glaucia1.htm (10 Jan 2001).

Focking, G.P. Um estudo sobre técnicas de avaliação de software educacional. http://www.inf.ufsc.br/ focking/ doc finalie.html (16 Jan 2001).

Gomes, H.P. Engenharia de Irrigação: Hidráulica dos Sistemas Pressurizados, Aspersão e Gotejamento. João Pessoa: Ed. Universitária, UFPB, 1994. 344p.

Moreira, M. O uso de computador na Educação: pressupostos psicopedagógicos. Educação em Revista, Belo Horizonte, n.4, p.13-17, 1986.

Souza, C.S. The semiotic engineering of user interface languages. International Journal of Man-Machine Studies, London, v.39, p.753-773, 1993. 